\title{
Determinants Of Oral Hygiene Status Among Junior Secondary School Students In Ilorin West Local Government Area Of Nigeria
}

\author{
Sa'adu Lateefat ${ }^{1}$, Musa O. I. ${ }^{2}$, Abu-Saeed Kamaldeen ${ }^{3}$, Abu-Saeed Muhammad \\ Buhari ${ }^{1}$, Saka A.O. ${ }^{4}$ \\ ${ }^{I}$ Microbiology Department, University of Ilorin Teaching Hospital, Ilorin. Nigeria \\ ${ }^{2}$ Department of Epidemiology and Community Health, University of Ilorin. Nigeria. \\ ${ }^{3}$ Research Unit, Peace Standard Pharmaceuticals, Ilorin. Nigeria. \\ ${ }^{4}$ Paediatric and Child health, University of Ilorin. Nigeria.
}

\begin{abstract}
Oral diseases are the most common form of chronic disease and are important public health problem because of their high prevalence, their Impact on individual and society, and expense of treatment. Toothache leads to school absenteeism, which is a ready indicator of children's health. A study to assess the oral health practices of junior secondary school students would reveal how far the nation has gone in promoting oral health using the WHO common risk factor approach. This work is thus, aimed at assessing oral hygiene status of respondents and determining some of the factors responsible for this status. A total of 399 students were used for the study. Multi stage sampling technique was used in selecting participants for the study. A semi-structured interviewer administered questionnaire was used to collect data. The collected data was analysed using EPIINFO 2007 software package. Oral examination was carried out by the dentist using the WHO Simplified Oral Hygiene Index (OHI-S). Result showed that $72 \%$ of respondents had fair oral hygiene status while the remaining had good oral hygiene status. Some of the factors influencing the oral hygiene status include frequency of sweet consumption ( $p=0.003)$, types of school respondents were attending $(p=0.000)$ and history of visit to the dentist $(p=0.000)$. Frequency of tooth brushing $(p=0.190)$ and history of past oral disease $(p=$ 0.784) did not have any influence on the oral hygiene status of respondents. These determinants will further aid the educators on areas to teach students in order to encourage and enhance good oral hygiene amongst them.
\end{abstract}

Keywords: Oral hygiene status, Oral diseases, Determinants, JSS students

\section{Introduction}

Oral health is defined as the standard of oral and related tissues which enables an individual to eat, speak and socialise without active disease, discomfort or embarrassment and which contributes to general wellbeing [1]

Oral diseases are the most common form of chronic disease and are important public health problem because of their high prevalence, their Impact on individual and society, and expense of treatment [2] Oral disease, such as dental caries, periodontal disease, tooth loss, oral mucosal lesions, oropharyngeal cancers, necrotising ulcerative stomatitis, cancrum oris (noma) and orodental trauma, which are serious public-health problem, is due to poor oral hygiene. Its impact on individuals and communities in terms of pain and suffering, impairment of function and reduced quality of life, is considerable [3]

Dental caries is one of the commonest oral diseases in children, severe caries detracts from children's quality of life: they experience pain, discomfort, disfigurement, acute and chronic infections, and sleeping and eating disruption as well as higher risk of hospitalization, high treatment costs and loss of school days with consequently diminished ability to learn All of which can be prevented by good oral hygiene. [4]

Tooth decay (dental caries) is one of the most common chronic childhood diseases, five times more common than asthma and seven times more common than hay fever. Toothache leads to school absenteeism, which is a ready indicator of children's health, worldwide more than fifty one million $(51,000,000)$ school hours are lost each year to dental- related illness [5]. Studies that involved children of other ages including 12 years of age in Nigeria gave caries prevalence of $13.9 \%$ and caries free level of $86.1 \%$. However, this is significant because of the population size [6].

Junior Secondary School pupils are children of ages 9- 15. This age is especially important, as it is generally the age at which children leave primary school, and thus in most countries, is the last age at which a reliable sample may be obtained easily through the school system. For this reason, it has been chosen as the global monitoring age for caries for international comparisons and monitoring of disease trends [7]. 
A study to assess the oral health practices of junior secondary school students would reveal how far the nation has gone in promoting oral health using the WHO common risk factor approach [8].

Furthermore, the study would encourage improvement and sustenance of good oral hygiene among the students. It will also lead to the institution of appropriate control measures by the students, their parents and the Government. The study can also be used as a base line data for future survey at both the state and national levels.

This work is thus, aimed at assessing oral hygiene status of respondents and determining some of the factors responsible for this status.

\section{METHOD}

Setting

The study was carried out in Ilorin West Local Government Area. Ilorin West is one of the 16 Local Government Areas in Kwara State, Nigeria and is one of the three LGAs that constitutes Ilorin metropolis. It is located along latitude $8^{0} 30$ North and longitude $4^{0} 35$ East of the equator. It has a land mass of $54^{0} 2 \mathrm{~km}^{2}$. There are 58 primary schools, 17 Government owned (public) senior secondary schools and 24 government-owned junior secondary schools of which 20 are unisex, 1 boys-only and 3 girls-only schools. However, there are 56 private secondary schools in the LGA. Altogether there are 11,034 enrolees in the senior secondary schools with male population of 5,486 and female population of 5,548, the total number of enrolees in the junior secondary schools is 15,232 with male population of 7,686 and female population of 7,546.

There are several health facilities in the Local Government, which are manned by the local Government, State Government and some Private bodies. The University of Ilorin Teaching Hospital temporary site owned and manned by the Federal Government is also situated in the Local Government Area. The Government Dental centre owned by the State Government is also situated within the University of Ilorin Teaching Hospital premises. There are four private dental clinics within the local Government.

\section{Study design and study population}

This is a descriptive cross sectional study. The study populations were junior secondary schools in Ilorin West Local Government Area. The sample populations were junior secondary school students of the selected schools from the list of schools in Ilorin West Local Government Area, both public and private unisex schools.

\section{Sample size determination} for the study.

Sample size was determined for populations greater than 10,000 [9] And 399 respondents were used

\section{Sample technique}

Multi stage sampling technique was used in selecting participants for the study.

1. Simple random sampling using table of random numbers was used to select two public schools (Government owned) out of the 21 mixed junior secondary schools and two private schools out of the 56 private secondary schools.

2. Proportionate allocation was used to select the number of students in each school using the population of junior secondary school(JSS) students in the school as a determinant factor, i.e school A with a population of 94 JSS students, the number of participants in the school was calculated as

\section{$\underline{94} \times$ Sample size}

Total no of students in JSS in the four selected schools

3. Proportionate allocation was also used to select the number of participants in each level. i.e. JSS1, JSS 2 and JSS3.

4. In each level, each arm was used as a cluster and simple random sampling technique using balloting method was used to select 2 arms in each level. i.e. two arms was selected from JSS1,two arms from JSS2 and two arms from JSS3.

5. Systematic sampling was used to select participants' required in each arm using a pre- determined sampling interval and the class register as the sampling frame, and the participants were selected at interval. 


\section{Data Collection and analysis}

A semi- structured interviewer administered questionnaire was used to collect data on some determinants of interest. Oral examination was carried out by the dentist using the WHO Simplified Oral Hygiene Index (OHI-S) developed by Greene and Vermillion. Six tooth surfaces were selected and examined for debris and calculus; the six surfaces examined were selected from two anterior and four posterior teeth. In the posterior portion of the dentition, the first fully erupted tooth distal to the second bicuspid, usually the first molar but sometimes the second or third molar is examined. The buccal surfaces of the selected upper molars and lingual surfaces of the selected lower molars are inspected. The anterior portion of the mouth, the labial surfaces of the upper right and lower left central incisors are scored. In the absence of either of these anterior teeth, a central incisor on the opposite side of the midline is substituted. After the scores for debris and calculus are recorded, the index values are calculated. For each individual, the debris scores are totalled and divided by the number of surfaces scored. The average individual or group score is known as the Simplified Debris Index (DI-S). The same methods are used to obtain the calculus scores or the Simplified Calculus Index (CI-S). The average individual or group debris and calculus scores are combined to obtain the simplified oral Hygiene Index (OHI-S). The collected data was analysed using EPI-INFO 2007 software package. Data was presented in form of percentage, cross tabulation of variables and p-values set at 0.05 .

\section{RESULTS}

Respondents' oral hygiene statue using WHO OHI-S is as presented on table 1. Cross tabulation of oral hygiene status with five factors which may influence it was done and p- values determined to test for statistical significance. Cross tabulation of oral hygiene status with frequency of sweet consumption was found to be statistically significant $(\mathrm{p}<0.05)$. Tooth brushing was also found not to influence the oral hygiene status of respondent with a p- value of 0.190 . Conversely, the type of school respondents were attending were found to be a factor influencing their Oral hygiene status $(\mathrm{p}<0.05)$. Similarly, there was association between respondents' history of visit to the dentist and their oral hygiene status (Table 6). Table 5 shows that there was no association between respondents' history of past oral disease and their oral hygiene status.

Table 1: Respondents' Oral Hygiene Status Using Who Ohi-S

\begin{tabular}{ll}
\hline ORAL HYGIENE & FREQUENCY (\%) \\
\hline Good & $112(28.0)$ \\
Fair & $287(72.0)$ \\
\hline TOTAL & $\mathbf{3 9 9}(\mathbf{1 0 0})$ \\
\hline
\end{tabular}

Table 2: Influence Of Frequency Of Sweets Consumption On Oral Hygiene Status

\begin{tabular}{lllll}
\hline & & \multicolumn{2}{l}{ ORAL HYGIENE STATUS } & Total \\
\cline { 3 - 4 } FREQUENCY & Everyday & 27 & & \\
OF SWod $(\%)$ & 127 & 154 \\
CONSUMPTIO & Thrice a week & 39 & 80 & 119 \\
N & Once in a week & 20 & 68 & 88 \\
& Rarely & 15 & 8 & 23 \\
Total & Never & 11 & 4 & 15 \\
\hline $\mathrm{p}=0.003$ & & 112 & 287 & 399 \\
\hline
\end{tabular}

Table 3: Influence Of Frequency Of Tooth Brushing On Oral Hygiene Status

\begin{tabular}{lllll}
\hline & & \multicolumn{2}{c}{ ORAL HYGIENE STATUS } & Total \\
\cline { 3 - 4 } FREQUENCY & Once daily & 67 & Gair & \\
OF TOOTH & Twice daily & 43 & 211 & 278 \\
BRUSHING & Weekly & 1 & 69 & 112 \\
& Rarely & 1 & 2 & 3 \\
\hline Total & & 112 & 5 & 6 \\
\hline $\mathrm{p}=0.190$ & & & 287 & 399 \\
\hline
\end{tabular}


Table 4: Influence Of Type Of School On Oral Hygiene Status

\begin{tabular}{|c|c|c|c|c|}
\hline \multirow{4}{*}{$\begin{array}{l}\text { TYPE OF } \\
\text { SCHOOL }\end{array}$} & \multirow{4}{*}{$\begin{array}{l}\text { Private } \\
\text { Public }\end{array}$} & \multicolumn{2}{|c|}{ ORAL HYGIENE STATUS } & \multirow{3}{*}{$\begin{array}{l}\text { Total } \\
70\end{array}$} \\
\hline & & Good & Fair & \\
\hline & & 43 & 27 & \\
\hline & & 69 & 260 & 329 \\
\hline Total & & 112 & 287 & 399 \\
\hline
\end{tabular}

Table 5: Influence Of History Of Past Oral Disease With Oral Hygiene Status

\begin{tabular}{lllll}
\hline & & \multicolumn{2}{l}{ ORAL HYGIENE STATUS } & Total \\
\cline { 3 - 4 } PAST & No & 80 & Fair & \\
HISTORY & Yes & 32 & 210 & 290 \\
OF ORAL & & & 77 & 109 \\
DISEASE & & & & \\
\hline Total & & 112 & 287 & 399 \\
\hline \multicolumn{1}{c}{$\mathrm{p}=0.784$} & & &
\end{tabular}

Table 6: Influence Of History Of Visit To Dentist On Oral Hygiene Status

\begin{tabular}{llllll}
\hline & & & \multicolumn{2}{l}{ ORAL HYGIENE STATUS } & Total \\
\cline { 3 - 4 } & & & Good & Fair & \\
HISTORY & OF & No & 53 & 278 & 331 \\
VISIT & TO & Yes & 59 & 9 & 68 \\
DENTIST & & & & &
\end{tabular}

\begin{tabular}{lccc}
\hline Total & 112 & 287 & 399 \\
\hline $\mathrm{p}=0.000$ & & &
\end{tabular}

\section{DISCUSSION}

From the result obtained above, the oral hygiene status of majority $(72 \%)$ of students was fair while the remaining (28\%) had good oral hygiene. This shows that there is every possibility for the most of the students to come down with oral disease in the future if nothing is done to improve this status. This study is in contrary with similar studies where oral hygiene status of students in selected secondary schools in Oshogbo, Nigeria showed that $86.8 \%$ of the students had good oral hygiene, $12.1 \%$ of them had fair oral hygiene and $1.2 \%$ had poor oral hygiene.[10]

Sweet consumption was found to be a cause of fair oral hygiene status $(\mathrm{p}=0.003)$. From table $2,73.3 \%$ of those who never consume sweet had good oral hygiene status while only $17.5 \%$ of respondents who consume sweets everyday had good oral hygiene. This goes to show that sweet consumption should be discouraged among respondents. This negative influence on oral hygiene status may be attributed to possible chance of the sweets consumed making the oral cavity suitable environment for microbial growth which may deteriorate the hygiene status generally. Thorough rinsing or cleaning of mouth should be encouraged immediately after consumption of sweets.

Tooth brushing has been found in studies to enhance oral hygiene in this study [10]. The result obtained in this study was in contrast to that as frequency of tooth brushing did not influence the oral hygiene (p> 0.05). Majority of those who rarely brush their teeth and those who brush once a day had fair oral hygiene status. Possible factor responsible for this may be attributed to how well the teeth were brushed. Poorly brushed teeth still harbours germs. Supervision of tooth brushing by parents may be important to enhance the oral hygiene status of the children.

A striking factor observed in this study was that the type of school the respondents were attending had a great influence on their oral hygiene status $(p=0.000)$. More percentage of students attending the private school had better oral hygiene status than those attending public school The result is in agreement with the widely held view that the private school students were from a relatively higher socio-economic status parents than the public school children and as a result there would be close monitoring of tooth brushing habits 
especially in the morning. This supports the result of Bamigboye and Akande in their study of oral hygiene status of students in selected secondary schools in Osogbo [10].

This study also shows that history of past oral disease among the respondents did not have influence on their oral hygiene status. Majority of those who had history of past oral disease and those who do not both had fair oral hygiene status.

In line with previous studies, this study has shown that visit to dentist has a positive influence on the oral hygiene status of the respondents [10]. Almost all (86.8\%) of respondents who had visited the dentist at one time or the other had good oral hygiene while the reverse was the case for those who had no history of visit to the dentist with $84 \%$ of them having fair oral hygiene status. This shows the importance of regular check-ups. Oral diseases are detected at very early stage and can be treated promptly. This goes a long way in promoting good oral hygiene.

\section{CONCLUSION}

In conclusion, majority of respondents had fair oral hygiene status. Factors influencing the oral hygiene status include frequency of sweet consumption, types of school respondents were attending and history of visit to the dentist. Frequency of tooth brushing, past history of oral disease did not have any influence on the oral hygiene status of respondents.

These determinants will further aid the educators on areas to teach students in order to encourage and enhance good oral hygiene amongst them.

\section{References}

Shujat H I,Nazli G S.The concept of oral health promoting schools in relation to oral health in east London, United Kingdom. Community dentistry, Pakistan oral and dental journal. 2006.28(2):279-282.

2. Locker D. Concept of oral health, disease and quality of life In: Slade G. Measuring oral health and quality of life. Chapel hill 1997. pp11-23.

3. Petersen PE. World Health Organizations' global policy for improvement of oral health. International Dental Journal.2008.58: $115-121$

4. Acs G, Ladolini G, Kaminsky S, Cisneros G J. Effect of nursing caries on body weight in a paediatric population. Paediatric dentistry. 1992. 14: 302-5

5. Cockburn A, Cockburn E. Epidemiology of dental caries. Cambridge university press. 1995

6. Aderinokun G.A, Oyemade A.O. Cultural beliefs and practices that influence oral health ad cae in a Nigerian community. Afri. Dent. J.1998.(12): 13-16.

7. Adegbemo AO. National survey of dental caries status and treatment needs in Nigeria, Int. Dent J, 1995; 45:35-44

8. WHO. Global goals for oral health.www.who.org. Assessed $21^{\text {st }}$ May, 2009

9. Araoye M O. Research methodology with statistics for health and social sciences. Nathadex pulishers, 2003.117-122.

10. Bamigboye O. Akande T M. Oral hygiene status of students in selected secondary schools in Osogbo, Nigeria. Nigerian Medical practitioner.2007.51(4):71-75 